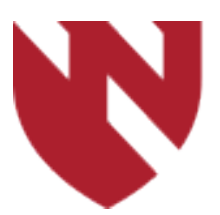

September 2020

\title{
Performance of the Lymph2Cx Cell of Origin Classifier of Diffuse Large B-Cell Lymphoma in Comparison to Two Immunohistochemical Algorithms
}

\author{
Katrina Lancaster-Shorts \\ University of Nebraska Medical Center \\ Ann Crowley \\ University of Nebraska Medical Center \\ Matthew Lunnin \\ University of Nebraska Medical Center \\ Allison Cushman-Vokoun \\ University of Nebraska Medical Center \\ Jane Yuan \\ University of Nebraska Medical Center
}

Tell us how you used this information in this short survey.

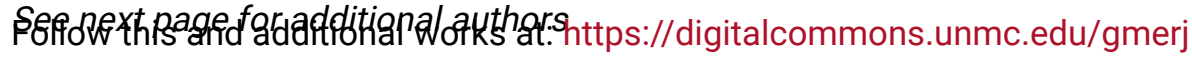

Part of the Higher Education Commons, and the Medicine and Health Sciences Commons

\section{Recommended Citation}

Lancaster-Shorts, K., Crowley, A., Lunnin, M., Cushman-Vokoun, A., Yuan, J., Amado, C., Greiner, T., Fu, K., , Qureishi, H. Performance of the Lymph2Cx Cell of Origin Classifier of Diffuse Large B-Cell Lymphoma in Comparison to Two Immunohistochemical Algorithms. Graduate Medical Education Research Journal. 2020 Sep 29; 2(1).

https://digitalcommons.unmc.edu/gmerj/vol2/iss1/66

This Conference Proceeding is brought to you for free and open access by DigitalCommons@UNMC. It has been accepted for inclusion in Graduate Medical Education Research Journal by an authorized editor of DigitalCommons@UNMC.For more information, please contact digitalcommons@unmc.edu. 


\section{Performance of the Lymph2Cx Cell of Origin Classifier of Diffuse Large B-Cell Lymphoma in Comparison to Two Immunohistochemical Algorithms}

\section{Creative Commons License}

\section{(c) (i) $\Theta($}

This work is licensed under a Creative Commons Attribution-Noncommercial-No Derivative Works 4.0 License.

\section{Authors}

Katrina Lancaster-Shorts, Ann Crowley, Matthew Lunnin, Allison Cushman-Vokoun, Jane Yuan, Catalina Amado, Timothy Greiner, Kai Fu, and Hina Naushad Qureishi 
quantity of MME prescribed at discharge correlated with higher pain scores at the first postoperative visit $(\mathrm{r}=0.25, \mathrm{p}=0.02)$ but not the second postoperative visit $(\mathrm{r}=0.17, \mathrm{p}=$ $0.15)$. There was no statistically significant association between MME prescribed and fracture characteristics or patient variables.

Conclusion: Postoperative opioid use correlated only with subjective, patient reported pain at the first postoperative visit, but did not correlate with injury mechanism, fracture characteristics, or patient variables.

https://doi.org/10.32873/unmc.dc.gmerj.2.1.063

\section{References}

1 Sairam Atluri, M.G.S., MD; Laxmaiah Manchikanti, MD, Assessment of the Trends of Medical Use and Misuse of Opioid Analgesics from 2004 to 2011. Pain Physician, 2014. 17: p. E119-E128.

2 Laxmaiah Manchikanti, M.A.S., BS, BA, Therapeutic Opioids: A Ten-Year Perspective on the Complexities and Complications the Escalating Use, Abuse, and Nonmedical Use of Opioids. Pain Physician, 2008. 11: p. S63-S88.
3 Boylan, M.R., et al., Patterns of Narcotic Prescribing by Orthopedic Surgeons for Medicare Patients. Am J Med Qual, 2018: p. 1062860618771190.

4 Attum, B., et al., Opioid Prescribing Practices by Orthopaedic Trauma Surgeons After Isolated Femur Fractures. J Orthop Trauma, 2018. 32(3): p. e106-e111.

5 Yu, N.N., et al., Persistence of Opioid Prescribing after a Forearm or Lower Leg Fracture. J Gen Intern Med, 2018. 33(3): p. 251-252.

6 Teng, Z., et al., Opioids contribute to fracture risk: a meta-analysis of 8 cohort studies. PLoS One, 2015. 10(6): p. e0128232.

7 Ping, F., et al., Opioids increase hip fracture risk: a meta-analysis. J Bone Miner Metab, 2017. 35(3): p. 289-297.

8 Buchheit, T., et al., Opioid exposure is associated with nonunion risk in a traumatically injured population: An inception cohort study. Injury, 2018.

9 Seth, P., et al., Quantifying the Epidemic of Prescription Opioid Overdose Deaths. Am J Public Health, 2018. 108(4): p. 500-502.

10 Bot, A.G., et al., Opioid use after fracture surgery correlates with pain intensity and satisfaction with pain relief. Clin Orthop Relat Res, 2014. 472(8): p. 2542-9.
11 Christensen, K.P., et al., The Effects of Anesthetic Technique on Postoperative Opioid Consumption in Ankle Fracture Surgery. Clin J Pain, 2016. 32(10): p. 870-4.

12 Finger, A., et al., Association Between Opioid Intake and Disability After Surgical Management of Ankle Fractures. J Am Acad Orthop Surg, 2017. 25(7): p. 519-526.

13 Helmerhorst, G.T.T., et al., Pain Relief After Operative Treatment of an Extremity Fracture: A Noninferiority Randomized Controlled Trial. J Bone Joint Surg Am, 2017. 99(22): p. 1908-1915.

14 McDonald, E., et al., Effect of Postoperative Ketorolac Administration on Bone Healing in Ankle Fracture Surgery. Foot Ankle Int, 2018: p. 1071100718782489.

15 Syed, U.A.M., et al., Neer Award 2018: the effect of preoperative education on opioid consumption in patients undergoing arthroscopic rotator cuff repair: a prospective, randomized clinical trial. $J$ Shoulder Elbow Surg, 2018. 27(6): p. 962-967.

\section{CD24 Expression in Follicular Lymphoma: An Alternative B-Cell Marker in Therapy Selected, Recurrent Lymphoma \\ Katrina Lancaster-Shorts ${ }^{1}$, Samuel Pirruccello'}

1 University of Nebraska Medical Center, Department of Pathology and Microbiology

Mentor: Samuel Pirruccello

Program: Pathology and Microbiology

Type: Original Research

Background: The rapidly expanding use of antigen targeted therapies, such as antiCD19, anti-CD20 and anti-CD22, in B-cell malignancies will require the application of additional B-cell-associated antigens in the assessment of residual disease. CD24 is a pan B-cell marker that undergoes significant surface density changes during normal maturation. In contrast to the loss of CD24 expression in normal follicles, we observed that follicle center derived lymphomas retain CD24 expression. Our aim was to determine the percentage of follicle center lymphomas with aberrant CD24 expression.

Methods: We reviewed 334 patients with a diagnosis of follicular lymphoma (FL; 228), large cell lymphoma of follicular origin (59) or B-cell lymphoma of follicular origin (47) by flow cytometry from October 2012 to August 2018. Cases without a confirmed tissue diagnosis of FL or diffuse large B-cell lymphoma (DLBCL) were excluded leaving 113 patients with FL, 38 patients with CD10positive DLBCL and 12 patients with mixed
FL/DLBCL. We analyzed the percentage of patients with CD24 positive lymphomas in each of the three diagnostic categories.

Results: We found that CD24 expression was retained in $89 \%$ of FLs $(101 / 113), 63 \%$ $(24 / 38)$ of DLBCLs and $42 \%(5 / 12)$ of mixed FL/DLBCL. Five cases of CD20 negative FL were $\mathrm{CD} 24$ positive.

Conclusion: Our results show the utility of aberrant CD24 expression in the identification of follicular lymphoma by flow cytometry.

https://doi.org/10.32873/unmc.dc.gmerj.2.1.065

\section{Performance of the Lymph2Cx Cell of Origin Classifier of Diffuse Large B-Cell Lymphoma in Comparison to Two Immunohistochemical Algorithms}

Katrina Lancaster-Shorts ${ }^{1}$, Ann Crowley ${ }^{1}$, Matthew Lunnin², Allison Cushman-Vokoun ${ }^{1}$, Jane Yuan¹, Catalina Amado ${ }^{1}$, Timothy Greiner ${ }^{1}$, Kai Fu¹, Hina Naushad Qureish ${ }^{1}$

${ }^{1}$ University of Nebraska Medical Center, Department of Pathology and Microbiology

${ }^{2}$ University of Nebraska Medical Center, Department of Internal Medicine, Division of Oncology and Hematology

Mentor: Naushad Qureishi

Program: Pathology and Microbiology

Type: Original Research

Background: Diffuse large B-cell lymphoma (DLBCL) is divided into cell-of-origin (COO) groups: germinal center B-cell (GCB), non-
GCB also known as activated B-cell (ABC) and intermediate/unclassified subgroups by mRNA gene expression profiling (mGEP). Immunohistochemical (IHC) classification algorithms, such as the Hans and Choi, were developed in lieu of mGEP on microarray, which could not analyze formalin fixed paraffin embedded (FFPE) tissue. The Nanostring Lymph2Cx assay is capable of
RNA gene expression profiling on FFPE tissue.

Methods: We studied 70 cases of DLBCL analyzed with the Lymph2Cx. Immunohistochemistry was performed on FFPE tissue sections using antibodies for CD10, BCL6, MUM1, GCET1 and FOXP1. Our aim was to determine the concordance 
rates between the Lymph2Cx assay and the Hans and Choi algorithms were calculated.

Results: By the Lymph2Cx assay analysis, 36 cases (51\%) were classified as GCB, 25 cases $(36 \%)$ were classified as $\mathrm{ABC}$ and 9 cases $(13 \%)$ were intermediate/unclassified. The Hans algorithm classified $37 / 70$ cases $(53 \%)$ as GCB and $33 / 70$ cases $(47 \%)$ as nonGBC. The Choi algorithm classified 14/36 cases $(39 \%)$ as GCB and $22 / 36$ cases $(61 \%)$ as ABC. After excluding the 9 intermediate/ unclassified cases by the Lymph2Cx assay,
61 cases classified by the Hans algorithm and 30 cases classified by the Choi algorithm were compared to the Lymph2Cx. Overall, $54(89 \%)$ of cases classified by the Hans IHC algorithm and Lymph2Cx assay were concordant. 22 (77\%) classified by the Choi algorithm and Lymph2Cx assay were concordant.

Conclusion: The Lymph2Cx assay is a useful tool to determine COO in DLBCL.

https://doi.org/10.32873/unmc.dc.gmerj.2.1.064

\section{Nontuberculous Mycobacterium (NTM) Infection in Aquatic Workers With Purified Protein Derivative (PPD) and Gold QuantiFERON Tests \\ Lavanya Ravipati ${ }^{1}$, Sarah A. Howard ${ }^{1}$}

${ }^{1}$ University of Nebraska Medical Center, Clarkson Family Medicine

Mentor: Sarah A. Howard

Program: Clarkson Family Medicine

Type: Case Report

Background: Nontuberculous mycobacteria (NTM) infections are commonly caused by Mycobacterium marinum and fortuitum with M. marinum more likely to cause skin infections. Aquatic environments are a potential source of contact with M. marinum and fortuitum. Patients with NTM infections may present with positive tuberculin purified protein derivative (PPD) and/or gold QuantiFERON tests. However, PPD cannot differentiate between NTM infection and other tuberculous infections caused by different mycobacterial strains. We present an asymptomatic patient who presented for further evaluation of an off-site positive PPD and gold QuantiFERON Test. Methods: Patient informed consent was
obtained for this case report.

Results: A 31 year-old, healthy, female marine biologist employed in an aquatic environment presented to the clinic with a positive PPD and a positive gold QuantiFERON test. Her job exposes her to sea creatures that maybe infected with Mycobacterium marinum and fortuitum. She denied any history that was suggestive of tuberculous infection. A referral was made to specialist service for further evaluation at which time a repeat gold QuantiFERON test was performed and was noted to be positive. Following this work up, the patient, understanding her likelihood of having exposure to M. Marinum and fortuitum, preferred to follow a conservative treatment approach to monitor for any symptoms of active tuberculosis and seek follow up as needed.
Conclusion: Clinicians should not downplay the importance of aquatic occupations and hobbies in patients who exhibit positive PPD and gold QuantiFERON test. Healthcare providers should consider NTM infection in their differential diagnosis when examining patient populations exposed to aquarium water, saltwater, and freshwater environments. Preventative apparel like waterproof gloves can protect the exposed skin from infection. Clinicians can prevent NTM infections by increasing awareness and promoting prevention measures in at-risk populations, particularly since infection can be prevented with appropriate protective attire.

https://doi.org/10.32873/unmc.dc.gmerj.2.1.074

\section{Chemoembolization of Hepatocellular Carcinoma With Parasitic Blood Supply From the Inferior Phrenic Artery Lei Yu' ${ }^{1 *}$, Alex Hodson ${ }^{2 *}$, Timothy Donovan ${ }^{1}$, Christphor Vargo ${ }^{1}$ \\ 1 University of Nebraska Medical Center, Department of Radiology \\ ${ }^{2}$ University of Nebraska Medical Center, College of Medicine \\ *These authors contributed equally to this work.}

Mentor: Christopher Vargo

Program: Radiology

Type: Case Report

Background: Transarterial chemoembolization (TACE) is a commonly used embolotherapy for unresectable hepatocellular carcinoma (HCC). The hepatic artery is usually the vessel of choice, however, up to $30 \%$ of HCCs can develop an extrahepatic collateral (EHC) supply and failure to recognize $\mathrm{EHC}$ can lead to treatment failure. The most common extra hepatic artery supplying $\mathrm{HCC}$ is the inferior phrenic artery (IPA), with right IPA and left IPA comprising up to $83 \%$ and $12 \%$ of all collaterals respectively. Certain imaging features can help predict the presence of IPA collaterals and should be considered at the time of treatment.

Methods: We reviewed one recurrent HCC after radioembolization and one residual $\mathrm{HCC}$ after chemoembolization to identify tumor characteristics associated with the formation of EHC, especially IPA collaterals. Procedural considerations during IPA embolization and common complications are also reviewed.

Results: Several factors raise the suspicion for EHC development, including large size, location (segment VII), and prior arterial embolization. Avoiding non-target embolization is crucial in treatment planning as inferior phrenic artery supplies the diagram, and rarely, the pericardium and bowel. Prophylactic embolization to nontumor feeding branches can limit non-target embolization. 